Aspergillus fumigatus 


\section{Contributions to Microbiology}

Vol. 2 


\title{
Aspergillus fumigatus
}

\section{Biology, Clinical Aspects and Molecular Approaches to Pathogenicity}

\author{
Volume Editors Axel A. Brakhage, Darmstadt \\ Bernhard Jahn, Mainz \\ Axel Schmidt, Wuppertal
}

46 figures, 10 in color, and 21 tables, 1999

KARGER $\begin{aligned} & \text { Basel·Freiburg } \cdot \text { Paris } \cdot \text { London } \cdot \text { New York } \cdot \\ & \text { New Delhi } \cdot \text { Bangkok } \text { Singapore } \cdot \text { Tokyo } \cdot \text { Sydney }\end{aligned}$ 


\title{
Contributions to Microbiology
}

formerly 'Concepts in Immunopathology' and

'Contributions to Microbiology and Immunology'

\section{Axel Schmidt}

PD Dr. med., FIBA

Bayer AG

Pharma Research Antiinfectives

Wuppertal;

Institute for Microbiology and Virology

University Witten-Herdecke, Germany

\author{
Library of Congress Cataloging-in-Publication Data \\ Aspergillus fumigatus: biology, clinical aspects, and molecular approaches to pathogenicity / \\ volume editors, Axel A. Brakhage, Bernhard Jahn, Axel Schmidt. \\ (Contributions to microbiology; vol. 2) \\ Includes bibliographical references and indexes. (hardcover : alk. paper) \\ 1. Aspergillus fumigatus. 2. Aspergillosis. I. Brakhage, Axel A. II. Jahn, Bernhard. \\ III. Schmidt, Axel, 1962- . IV. Series. \\ [DNLM: 1. Aspergillus fumigatus - pathogenicity. 2. Aspergillosis - microbiology. \\ QW 180.5.D38 A8392 1999] \\ QR201.A85A86 1999 \\ $579.5^{\prime} 657-\mathrm{dc} 21$ \\ ISBN 3-8055-6714-6
}

Bibliographic Indices. This publication is listed in bibliographic services, including Current Contents ${ }^{\circledR}$ and Index Medicus.

Drug Dosage. The authors and the publisher have exerted every effort to ensure that drug selection and dosage set forth in this text are in accord with current recommendations and practice at the time of publication. However, in view of ongoing research, changes in government regulations, and the constant flow of information relating to drug therapy and drug reactions, the reader is urged to check the package insert for each drug for any change in indications and dosage and for added warnings and precautions. This is particularly important when the recommended agent is a new and/or infrequently employed drug.

All rights reserved. No part of this publication may be translated into other languages, reproduced or utilized in any form or by any means electronic or mechanical, including photocopying, recording, microcopying, or by any information storage and retrieval system, without permission in writing from the publisher.

C) Copyright 1999 by S. Karger AG, P.O. Box, CH-4009 Basel (Switzerland)

Printed in Switzerland on acid-free paper by Reinhardt Druck, Basel

ISBN 3-8055-6714-6 
In Remembrance of

Manfred W. Plempel (1930-1994)

Clinical Mycologist and Pioneer in Azole-Antifungal Research 


\section{Contents}

IX Preface

XI Editorial Preface

1 J.B. Georg W. Fresenius and the Description of the Species Aspergillus fumigatus

Schmidt, A.; Schmidt, D.I. (Witten-Herdecke)

5 The Genus Aspergillus with Special Regard to the Aspergillus fumigatus Group

Samson, R.A. (Baarn)

21 Pathogenesis and Clinical Presentation of Aspergillosis Rüchel, R.; Reichard, U. (Göttingen)

44 Epidemiology and Molecular Basis of the Involvement of Aspergillus fumigatus in Allergic Diseases

Crameri, R. (Davos)

57 Host Defense Mechanism in Aspergillus fumigatus Infections Schneemann, M. (Stanford, Calif.); Schaffner, A. (Zurich)

69 Antigen and DNA Patterns Characteristic of Aspergillus fumigatus Latgé, J.P. (Paris)

88 Laboratory Diagnosis of Aspergillus fumigatus-Associated Diseases Kappe, R.; Rimek, D. (Heidelberg)

105 Therapy of Aspergillus fumigatus-Related Diseases Ellis, M. (Abu Dhabi)

130 Animal Models of $A$. fumigatus Infections Shibuya, K.; Naoe, S.; Yamaguchi, H. (Tokyo) 
139 Problems of Antifungal in vitro Testing in Aspergillus fumigatus Espinel-Ingroff, A. (Richmond, Va.)

149 Transformation Systems of Aspergillus fumigatus:

New Tools to Investigate Fungal Virulence

d'Enfert, C. (Paris); Weidner, G. (Darmstadt); Mol, P.C. (Paris);

Brakhage, A.A. (Darmstadt)

167 Interactions between Aspergillus fumigatus and Host Matrix Proteins Bouchara, J.-P.; Sanchez, M.; Esnault, K.; Tronchin, G. (Angers)

182 Aspergillus fumigatus-Secreted Proteases As Antigenic Molecules and Virulence Factors

Monod, M.; Jaton-Ogay, K. (Lausanne); Reichard, U. (Göttingen)

193 Chitin Synthase Genes of Aspergillus Species

Horiuchi, H.; Takagi, M (Tokyo)

205 Pigment Biosynthesis and Virulence

Brakhage, A.A.; Langfelder, K. (Darmstadt); Wanner, G. (München);

Schmidt, A. (Wuppertal); Jahn, B. (Mainz)

216 Author Index

217 Subject Index 


\section{............................. \\ Preface}

In medicine, life-threatening systemic mycotic infections are gaining importance as opportunistic infections. This is due to the steadily increasing number of immunocompromised individuals: AIDS and cancer patients, organ transplant patients, or patients under intensive care or predisposing concomitant treatment regimens such as steroid therapy, therapy with other immunosuppressives, and antineoplastic and/or antibiotic chemotherapy. Further, fungal organisms can in the meantime also be attributed to nosocomial infections; pathogenic fungi belong to the fourth most isolated pathogens in intensive care units. Apart from systemic yeast infections, systemic mycoses can often be attributed to hyphomycetes, mostly to Aspergillus species, predominantly A. fumigatus. Most of these systemic Aspergillus infections are lifethreatening with an extremely high mortality rate, even after appropriate antimycotic therapy regimens. This is mainly due to the often severe underlying immunosuppression of the host.

In general, infections/disorders caused by Aspergillus species, in particular A. fumigatus, can be divided into allergic reactions, generalized invasive and semi-invasive/restricted infections, and diseases resulting from mycotoxin exposure. All these aspects are discussed extensively and presented in this book which includes clinically oriented chapters, diagnostics, therapy, and new approaches in molecular biology.

This exciting project could not have been successful without the excellent editorial collaboration of my friends and colleagues Axel A. Brakhage (Darmstadt) and Bernhard Jahn (Mainz). I would like to thank both of them very much for constructive and effective discussion during this project and especially the cooperation with the inspiring ongoing research on Aspergillus-related topics as well as their amicable way of interaction and information exchange.

Witten-Herdecke, February 1999

Axel Schmidt Series Editor 


\section{Editorial Preface}

Fungal pathogens have begun to rival their bacterial counterparts as a significant problem in many settings. Death from fungal infection and bacterial infection are now almost equal in number in neutropenic patients. Besides the rise in occurrence of nosocomial yeast infections, infections with mold pathogens have emerged as an increasing risk faced by patients under sustained immunosuppression. Species of the Aspergillus family account for most of these infections and in particular Aspergillus fumigatus can be regarded as the primary mold pathogen. The improvement in transplant medicine and the therapy of hematological malignancies is often complicated by the threat of invasive aspergillosis. Specific diagnostics are still limited as are the possibilities of therapeutic intervention, leading to the disappointing fact that invasive aspergillosis is still associated with a high mortality rate that ranges from 30 to $90 \%$.

However, the spectrum of diseases related to A. fumigatus is rather heterogeneous and exceeds that of a mere opportunistic pathogen: Colonization with restricted invasiveness is seen in the immunocompetent host, disseminated infections in the immunocompromised patient, and allergic disorders have long been known to be caused by A. fumigatus antigens.

While preparing this book, we realized that the heterogeneity of aspects which are important to be outlined in a book about $A$. fumigatus pathogenicity is probably comparable to the heterogeneity concerning the interests and backgrounds of our potential readers. Hence, our main objective to provide a concise and up-to-date report on A. fumigatus as the predominant human mold pathogen was guided by three main intentions.

First, we wished to provide the reader with a background on A. fumigatus biology, including physiology and taxonomy as a basis for further understanding of the more-detailed aspects related to the pathogenicity of $A$. fumigatus.

The second objective was to give a condensed overview of the medical aspects of $A$. fumigatus. Host defense mechanisms, clinical signs and underlying 
pathogenetic mechanisms of the different forms of A. fumigatus-related diseases are presented. The chapters on diagnostics and typing also include new molecular-based methods. The therapeutic strategies available against A. fumigatusrelated diseases are summarised. In addition, information on the development of new antifungal drugs and susceptibility studies is given.

The question what makes $A$. fumigatus the predominant mold pathogen has not been resolved yet. Hence, our third intention was to give an overview about the current state of search for determinants of $A$. fumigatus virulence. Different chapters are dealing with the identification of potential virulence factors or physiological characteristics of A. fumigatus making it an aggressive opportunistic pathogen. Furthermore, the current knowledge on some potential targets for antifungal drugs like chitin synthases is presented. Most of the investigations which are summarised in these chapters use molecular genetics and protein chemistry as tools. In our view, these techniques represent the key technologies in the further elucidation of $A$. fumigatus pathogenicity. They are presented in various chapters, each covering a different aspect.

We are deeply indebted to the authors of the chapters in this volume whose intelligent and diligent efforts made this joint project possible. We are grateful to them for the care and energy with which they approached this work. We thank the series and volume editor Axel Schmidt for his enthusiasm when preparing this volume and for his excellent scientific cooperation and friendship. The editoral and production staff of S. Karger AG are gratefully acknowledged for their fruitful and professional collaboration.

Axel A. Brakhage/Bernhard Jahn Darmstadt/Mainz 